\title{
Research on Home Old Aged Support Model in Rural Areas

\author{
Dan Liu ${ }^{1, a}$
}

${ }^{1}$ Yunnan College of Business Management, Kunming, Yunnan, 650033

\author{
Keywords: Rural Area; Old Aged Support Model; Home Pension
}

\begin{abstract}
With the emergence of the phenomenon of population aging, the number of rural elderly population is increasing. Community home care model is the most suitable for rural areas in China's old-age model, in order to meet their material needs, life care service needs, medical service needs and leisure and entertainment needs, should make full use of government, community, family trinity service advantages, policy support and financial support role, play community advantages for home care services. In order to solve the needs of the elderly in the rural areas, the state gives the policy and funds to support the construction of the old-age education system. Improve the community management models give full play to the role of family support to solve the problem of rural areas of old age. This paper studies the coping strategies by analyzing the problems, which is of great significance to promote the construction of the new rural old-age system.
\end{abstract}

\section{Theoretical Introduction of Home Old Aged Support}

Home old aged support refers to the combination of social resources, pension structure services and family services as one of the pension model. The elderly living in the home, while the family and the elderly for the elderly to provide pension services, the other side and the community for the elderly to provide pension services, so that the quality of life of the elderly to improve and improve. The source of the old-age pension model in the home-aged model includes the family and the society, and the proportion of the society is larger. Social provision of pension resources, including pension services and pension services in two forms.

The content and level of the pension is very rich, it should be the economic support, life care and spiritual comfort of the organic unity of the elderly is the community-based, family as the core, professional services to rely on, for the elderly to provide daily services for the elderly integrated The service system can be seen from the above analysis. Home care on the one hand can reduce the cost of pension agencies set up, on the other hand can reduce the cost of pension, and to a certain extent, ease the country's economic pressure in the pension. The elderly in the home pension model can get the family's life care, without purchase old-age services, so that the pressure on the rural economy to reduce the family in the process of taking care of the elderly will not affect the production, to promote economic development ${ }^{[1]}$.

In the home care model, through the government and social pension service system of continuous improvement, the elderly in the old-age care and old-age services and other parties can be effectively protected, not on the family members of the well-being and quality of life impact. Therefore, this pension model can achieve sustainable development. At present, the family pension in rural areas is difficult to effectively solve the old-age problem of the elderly in rural areas. In this unique economic and cultural background, the rural home is necessary to provide a multi-level service related to the life of the elderly, including the material Supply, life care, health care, leisure and so on, of course, the supply of these services need pension agencies, communities, local governments and other multi-resource integration in many rural areas.

\section{Main Problems in Home Old Aged Support of Rural}

Home care is very suitable for rural areas, but the current development in rural areas is not optimistic, the main issues are the following: rural home care services, lack of funds in the rural areas behind the economic needs of strong support for the current rural home, shortcomings in the existing financing mode. In the pilot area, the funds for the rural home care service are derived from: 
the financial allocation, the village self-financing, the social donation and other financial allocations should be the main fund, the actual situation is that after the two parts of the non-stop regulatory arrangements for the funds in support of the current rural home pension operation and thus the source of funds is unstable and small size has been from the root of the constraints of the rural home pension ${ }^{[2]}$. Fig.1 shows main problems in home old aged support of rural.

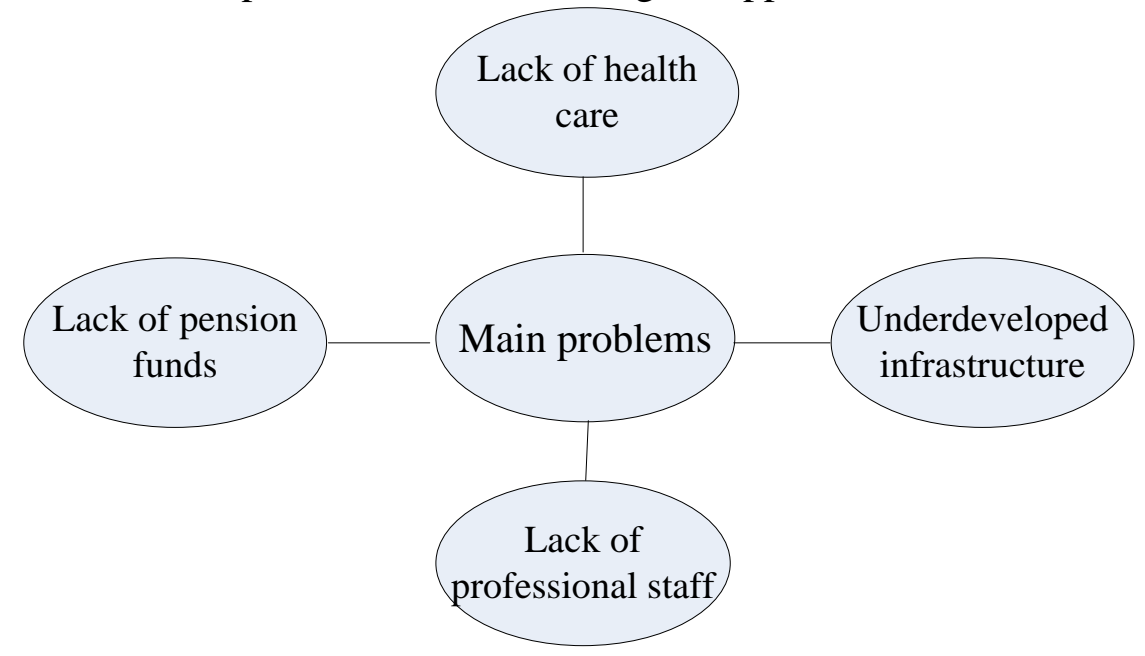

Fig. 1.The main problems in home old aged support of rural

The narrow coverage of services has been the focus of the pilot rural areas of the elderly services are mainly economic difficulties, frail, elderly living Pratt \& Whitney home care services are not generally carried out in rural areas. Inadequate service projects currently pilot services are mainly life care and health care life care to carry out the project, including cooking, meal delivery, cleaning, and health care is mainly physical examination, blood pressure and other simple routine medical services. Rural areas, the lack of professional services for the elderly, most of the lack of full-time management staff did not receive professional management training, a certain extent, hindered the deepening of the home pension; another full-time service staff is also a lack of home service services mainly by the volunteers, caring people and so on As there is no professional knowledge of learning and training, the current level of life care services to be improved, although some areas to establish full-time service team, but by the level of cultural constraints led to the service level is not high.

Rural residential pension infrastructure must be lagging behind, the number of basic service facilities, rural home care infrastructure construction is very slow to meet the basic needs of the elderly activities center, fitness places and other serious deficiencies; secondly, the distribution of old-age service facilities and demand does not match The geographical area of the administrative region of the rural areas is scattered, and the old-age service facilities are often located near the town, which results in the utilization of the old service facilities is not high and the actual needs of the elderly have not been met ${ }^{[3]}$.

\section{Countermeasures and Suggestions for Providing the Aged in Rural}

In order to improve the level of rural home care services must pay tribute platform construction, including two aspects: one is the public facilities platform, one industrial platform. In the public facilities platform, rural home care services should be combined with the new rural construction, as a breakthrough in the development of rural pension business, solve the problem of rural pensions. Stable and sufficient source of funds is to gradually promote the basic guarantee of rural home care services ${ }^{[5]}$.

At present, the funds of the rural home care work are mainly from the village (community) self-financing, social donations, government funding support is not enough, small-scale funds, It is also unstable. Therefore, the government departments should implement a more active and effective policy, on the basis of increasing financial investment to actively guide and guide social organizations and individuals involved, to encourage social forces to donate, so that the home care 
service socialization and marketization. First of all to determine the scientific object of the first focus, give priority to the protection of rural poverty, age, sick, disabled elderly and empty nest elderly pension service needs, and then extended to the general needs of the elderly followed by continuous improvement services first focus on the needs of the most Urgent service items: life care services and blood pressure, physical examination and health talks and counseling services. Fig.2 shows countermeasures and suggestions for providing the aged.

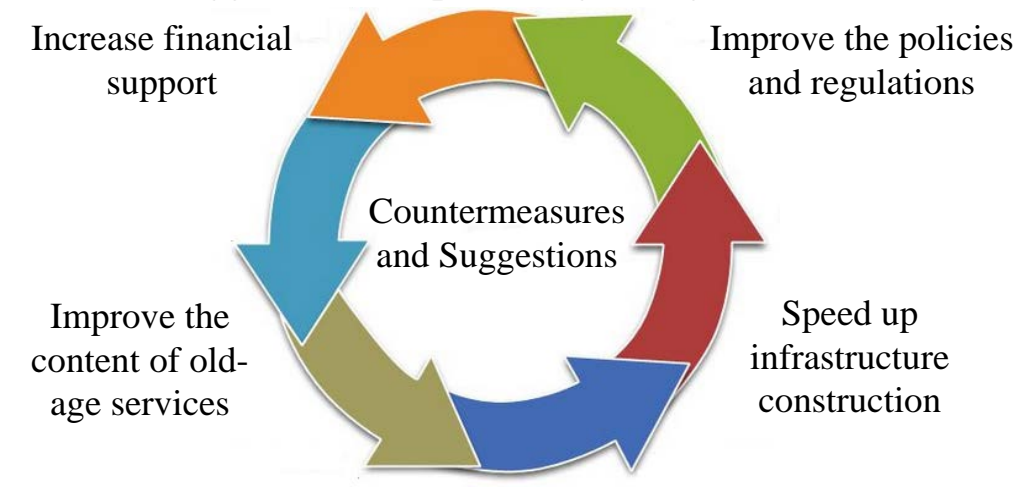

Fig. 2.The countermeasures and suggestions for providing the aged

The necessary infrastructure is the basic conditions for the work of rural home care services, such as home care service center (station), elderly activity center, health care room and other infrastructure construction is the development of rural home care services, the primary task combined with local community construction The actual situation, according to the actual needs of the elderly, the various departments should coordinate the integration of multi-resources, accelerate the construction of basic service facilities, in order to promote life care, health care, sports and entertainment services to carry out. Improve the rural home care services policies and regulations, the rural home care services for the main body, pension content, pension, pension environment and other aspects of local legislation to protect the work to ensure that rural housing pension in the financial security, tax concessions, service personnel, Standards, assessment of supervision and other aspects can be the corresponding legal and policy support to enhance the implementation of rural home care services to achieve the rural home care services legalization, institutionalization and standardization.

\section{Function Positioning of the Government}

As a strong complement to the rural social security policy, the rural home pension model has a huge role in solving the problem of rural old-age. The government should also provide a good economic environment for rural home care, through the development of a series of relevant measures to promote the development of rural economy, reduce the resistance of home support in rural development. At the same time, the government should also establish and improve the rural housing supervision mechanism and system, continue to increase supervision and guidance efforts, by standardizing the behavior of rural home care services to ensure the quality of service. Specifically, the government in the rural elderly home care model in the functional orientation should include the following aspects.

In recent years, our government functions will be more rights and affairs to the community to bear. Similarly, the government in the rural home pension development process also need to change the function, to mobilize the community to participate in the management of the power. Home care services should be government-led, multi-subject participation. The government in the development of home care process is to perform the organization and leadership functions, other participants in the government under the leadership of the elderly to provide a variety of services. Only by giving full play to the organization and leadership functions of local governments at all levels, the participants can form a positive interaction, so as to promote the healthy development of rural home care. Through the establishment of the evaluation system, the object and the demand of the care service should be evaluated to provide the targeted service for the elderly, so that the utility of the 
social service resources can be maximized.

The smooth implementation of social security policy is inseparable from the government's financial support. In rural areas, the lack of funds provided by the main body, the elderly pension funds mainly rely on personal, family and government support, especially in many poor areas, the elderly pension is too low, and the family and the lack of economic sources, only Rely on the government to provide support. Government is the main body of public expenditure, and home care is an important part of social welfare, Government should provide support for home support for the elderly. The government should actively carry out the supervision and evaluation function in the rural home care. The evaluation of the effect of home care services can provide a basis for further strengthening the supervision of rural home care. Therefore, the government should set up a detailed evaluation index system and supervision system for the effect of the implementation process in rural areas, the satisfaction degree of the people, and evaluate the effect of the home care service.

\section{Conclusions}

The old-age model of home is the effective integration of family pension and institutional pension, which is one of the key goals of the future construction of the pension industry in China. There are some modes of government service, community service or community service in China. Fastening the economy, the underdevelopment of the family, the imbalance of the family structure, the lack of old-age facilities, the old-age pension model should be the first choice for the old-age way to build rural home care model should focus on improving rural basic medical care. With the rural home care services carry out and promote, because of its remarkable results and get more rural elderly identity. The development of the rural home-aged model is a complex systematic project. Based on the detailed understanding of the present situation and existing problems of the rural home-aged model, the paper puts forward some suggestions to promote the further development of the rural elderly.

\section{References}

[1] HUANG Li-li, LU Guan-chao The Value and Safeguard Countermeasure of the Rural Old-age Care Model in China under the Background of Population Aging TIAN Zhen-hui, 2012, (24): 19.

[2] Luyao Ming, Li Jingsi, Zhang Xiaoyan, Wu Bing administrative issues concerning the implementation of home care service model - based home care Baoding survey, data analysis theory, 2012, (25): 14.

[3] Gao Hong, Social Support System for Urban Community Elderly Home Care - A Case Study of Qingdao City Day "Nanjing Normal University (Social Science Edition), 2011, (6): 54.

[4] Ji Lei, Zhang Xueze, Zhang Yingjie, Southern Jiangsu urban community home new model to explore the field of modern business, 2014, (11): 16.

[5] Fu Mei, build rural community home care model Legal Thought - A Case Study of Hainan Tian Henan Police College, 2014, (2): 32. 